\title{
Experimental and Analytical Study on CFRP strengthened AAC panels
}

\author{
Bo Wang ${ }^{1, a}$, Xinli Kong ${ }^{1, b}$, Hong Wang ${ }^{2, c}$, Lu Dong ${ }^{1, d}$ \\ ${ }^{1}$ State Key Laboratory of Disaster Prevention \& Mitigation of Explosion \& Impact, Army Engineering \\ University, Nanjing 210007, China \\ ${ }^{2}$ Beijing Canbao Architec Design Institute, Beijing 100036, China \\ awbo5503@163.com,b75974502@qq.com, cwwanghong80@126.com, d9779062@qq.com
}

Keywords: Composite structures; Fiber reinforced polymers (FRP); Autoclaved aerated cellular concrete (AAC); Structural analysis.

Abstract. A series of quasi-static tests were conducted to investigate the load capacity of panels constructed with plain autoclaved aerated cellular concrete (AAC). Test results verified the effectiveness of CFRP plates increasing the ductility and load capacity of AAC panels. A theoretical analysis was conducted to explain the failure mechanism and to predict the ultimate bearing capacity of AAC/CFRP panels, based on the shear strength theory. The predicted results were compared with three-point bending tests data using MTS Quasi-static Hydraulic Servo Testing System, the feasibility and validity of the theoretical predictions are demonstrated for minor difference.

\section{Introduction}

AAC is not only an extension of reinforced concrete but also is now considered as a member of the family of laminated composites, it can be reinforced with steel, or fiber reinforced polymeric (FRP) meshes.

In this investigation, the AAC panels chosen as matrix were reinforced ones, and had been practically applied. The main objective of this study is to testify the effectiveness of strengthening AAC structural elements through CFRP wrapping method, as well as to examine the ultimate load capacity, and failure mechanism of FRP/AAC panels with different strengthened methods. Further, the influence of reinforcing steel bar was taken into account. Three types of specimens were investigated: (1) reinforced AAC panels (RAP), (2) plain AAC panels strengthened with unidirectional CFRP plates for flexural reinforcement (UCPAP), and (3) reinforced AAC panels strengthened with bidirectional CFRP plates for flexural and shear reinforcement (BCRAP). Besides, a plain AAC panels (PAP) was tested for comparison. Table 1 shows the variables and constants used in this paper.

\section{Strengthening method}

The FRP/AAC panels investigated were composed of CFRP laminates as a face sheet (skin) and AAC panels as a core. Tab. 1 lists the mechanical properties of the AAC, the density of which was $625 \mathrm{~kg} / \mathrm{m} 3$. And Tab. 2 summarizes the mechanical properties of carbon fibers sheet, and epoxy resin used in this research. Fig. 1 shows the reinforcement drawing of these AAC panels. Each AAC panel was measured $1200 \mathrm{~mm} \times 600 \mathrm{~mm} \times 100 \mathrm{~mm}$, about $50 \mathrm{~kg}$, with 18 steel bars in it $(9$ bars in each row). The diameter of each bar is $5 \mathrm{~mm}$. 
As shown in Fig. 2, in this study, four types of AAC panels have been made, the schematic diagrams for the two types of CFRP wrapping methods are also shown.
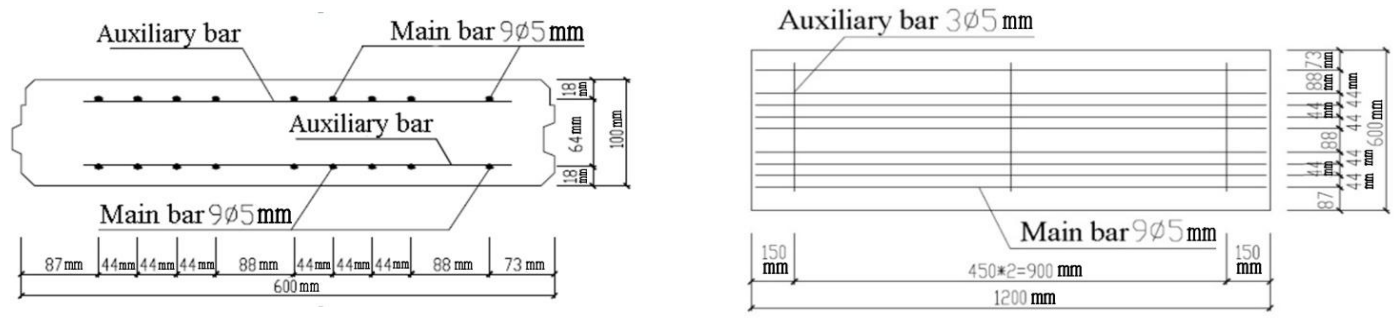

Fig.1 Reinforcement Drawing of AAC panels

Table 1 Mechanical properties of the AAC/FRP panels

\begin{tabular}{ccccc}
\hline Variables & Definition & Constants & Definition & Value \\
\hline$M_{u}$ & Maximum bending & $b$ & Width of panel & $600 \mathrm{~mm}$ \\
$P_{u}$ & moment & $f_{c t}$ & Tensile strength of concrete & $0.3 \mathrm{MPa}$ \\
$V_{A A C}$ & Shear strength contributed & $f_{c u}$ & $\begin{array}{c}\text { Compressive strength of } \\
\text { by AAC }\end{array}$ & $3 \mathrm{MPa}$ \\
$V_{u}$ & $\begin{array}{c}\text { Maximum shear } \\
\text { resistance }\end{array}$ & $f_{F R P}$ & Tensile strength of CFRP & $3.4 \mathrm{GPa}$ \\
$V_{f r p}$ & $\begin{array}{c}\text { Shear strength contributed } \\
\text { by CFRP }\end{array}$ & $f_{s}$ & Tensile strength of steel bar & $370 \mathrm{MPa}$ \\
\hline
\end{tabular}

Table 2 Mechanical properties of epoxy resin CFRP composite

\begin{tabular}{ccccc}
\hline Property & Tensile Strength & Elasticity Modulus & Thickness & Density \\
\hline CFRP sheet & $3.4 \mathrm{GPa}$ & $140 \mathrm{GPa}$ & $0.167 \mathrm{~mm}$ & $1780 \mathrm{~kg} / \mathrm{m}^{3}$ \\
Epoxy resin & $72.4 \mathrm{MPa}$ & $3.17 \mathrm{GPa}$ & $0.2 \mathrm{~mm}$ & $2150 \mathrm{~kg} / \mathrm{m}^{3}$ \\
\hline
\end{tabular}

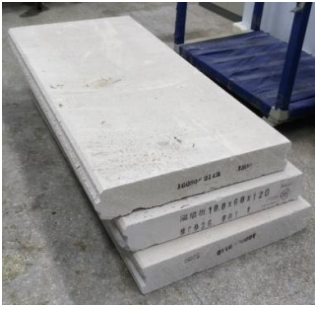

(a)

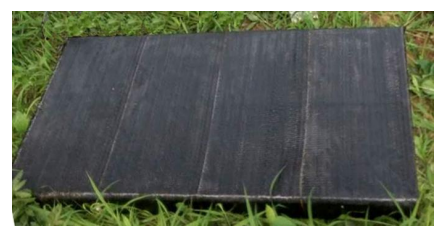

(b)

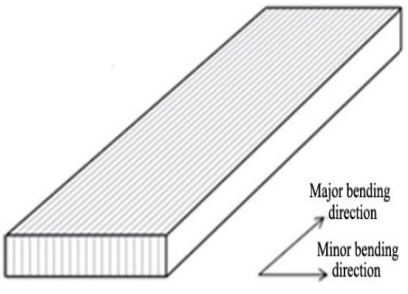

(c)

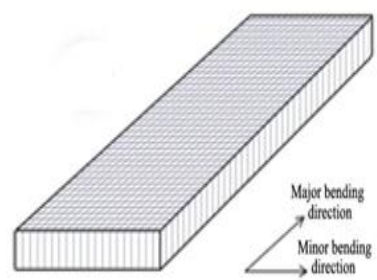

(d)

Fig. 2 (a) Un-strengthened and (b) strengthened ACC panels; schematic diagrams for (c)CFRP (d) BCRAP

\section{Experimental method and results}

The three-point bending tests were applied to investigate the structural response of the specimen. The load was applied at a uniform rate of $0.6 \mathrm{~mm} / \mathrm{min}$, using MTS Quasi-static Hydraulic Servo Testing System, as shown in Fig. 3. The displacement at the mid-span of the panel and the real-time load were automatically recorded by computer. The span length of specimen is $1000 \mathrm{~mm}$. The maximum mid-span deflection and load carrying capacity of the specimens are summarized in Table 3.

The detailed bending deformation and failure mode of the specimens were demonstrated in Wang's study ${ }^{[1]}$. Fig. 4 shows schematic step diagrams for the failure of BCRAP. The wrinkling of FRP in compression occurred, followed at once by FRP debonding break, meanwhile the AAC panel cracked at the maximum shear. The broken of the bonding layer between AAC and FRP is the reason for failure. 

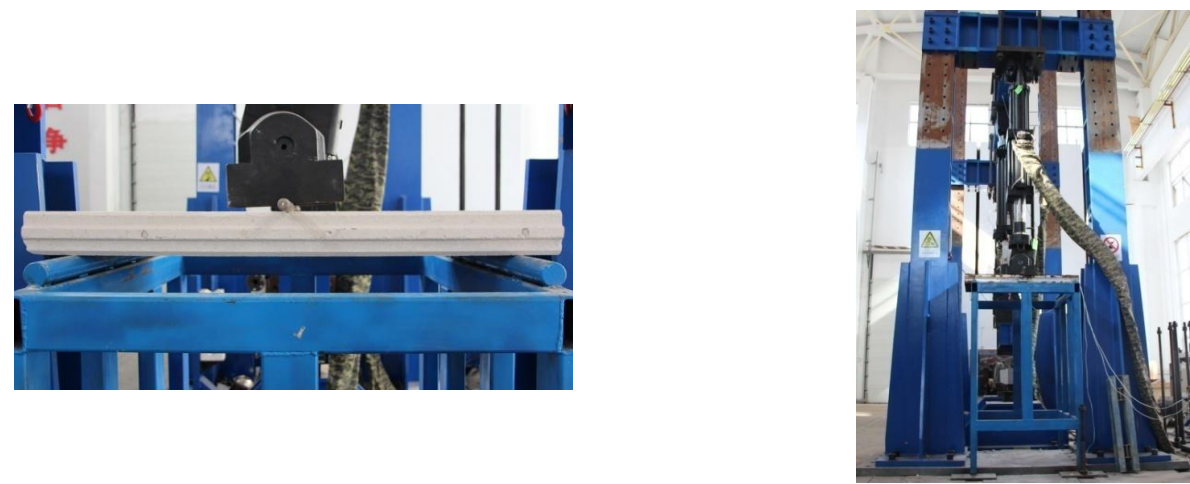

Fig. 3. Three-point test frame by MTS Quasi-static Hydraulic Servo Testing System

Table 3 Critical mid-span deflection of FRP/AAC panels

\begin{tabular}{cccc}
\hline Panel & Reinforcement method & Maximum Load $(\mathrm{kN})$ & Critical mid-span deflection $(\mathrm{mm})$ \\
\hline PAP & No & $<2$ & failed \\
RAP & Reinforced & 11.42 & 4.02 \\
UCPAP & CFRP & 11.59 & 3.08 \\
BCRAP & Reinforced + & 20.70 & 4.54 \\
\hline
\end{tabular}

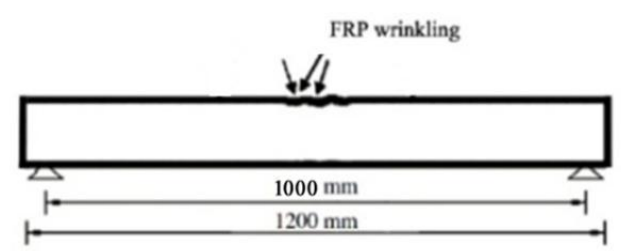

(a)

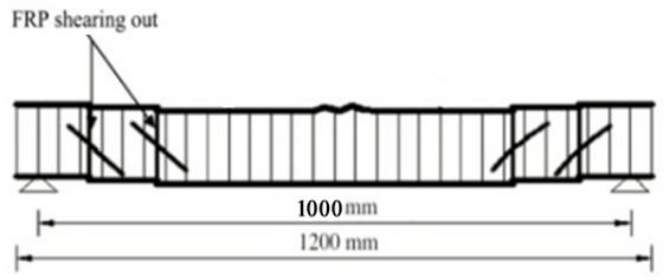

(c)

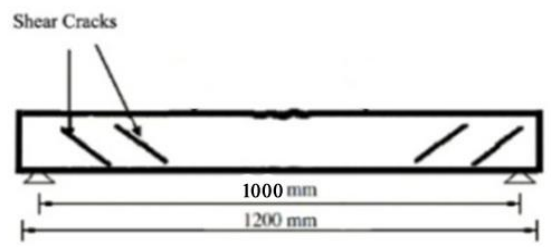

(b)

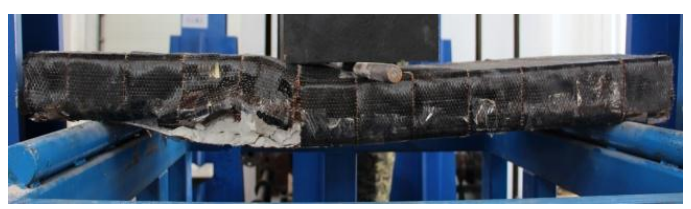

(d)

Fig. 4 Schematic step diagram for failure of BCRAP: (a) Step 1, FRP Wrinkling, (b) Shear cracks of AAC, (c) FRP Shearing out, and (d) Photo of specimen's failure

\section{Analyses}

As the damage of AAC panels is brittle crack, the plastic deformation could be ignored before crack failure. Furthe, there is no significant deformation or damage on the other parts of the beams except the cracking region. So before crack failure, the measured mid-span deformation is assumed as elastic stage in this paper. As shown in Fig. 5(a), the panel was approximately simply supported and loaded by a concentrated load, $\mathrm{P}$, at the mid-span. The internal forces of structure are expressed as 


$$
\left\{\begin{array}{l}
\mathrm{N}=\mathrm{P} / 2 \cdot \tan \theta \\
\mathrm{V}=\mathrm{P} /(2 \cdot \cos \theta) \\
\mathrm{M}(\mathrm{x})=\mathrm{P} / 2 \cdot(\mathrm{L} / 2-\mathrm{X})
\end{array}\right.
$$

The experiments reveal two failure modes: bending failure (PAP) and shear failure (the others). Eq.(1) shows that the maximum load applied on the panel is associated with the failure mode, in other words, the maximum bending moment or shear capacity of cross-section is the key factor. If the panel was destructed by bending failure, the peak load, $\mathrm{Pu}$, is given by

$$
\mathrm{P}_{\mathrm{u}}=4 \mathrm{M}_{\mathrm{u}} / \mathrm{L}
$$

where $\mathrm{M}_{\mathrm{u}}$ is the ultimate bending moment of the cross-section, given by

$$
\mathrm{M}_{\mathrm{u}}=\left(\mathrm{bh}^{2} \sigma_{\mathrm{ct}}\right) / 6
$$

Where $\sigma_{\mathrm{ct}}$ is the tensile strength of concrete, and equals to $0.3 \mathrm{MPa} . \mathrm{b}$ and $\mathrm{h}$ denote the width and thickness of the panel's cross-section. Therefore, the peak load of the panel predicted by Eq. (2) and (3) is $1.2 \mathrm{kN}$, less than the original load $2 \mathrm{kN}$, which explains the measurement failure of PAP.

In terms of the other specimens, the overall performance and the load carrying capacity had been greatly improved because of the strengthened reinforcement and CFRP sheets. The failure mode was induced by shear failure near the support, so the peak load is determined by

$$
\begin{gathered}
\mathrm{P}_{\mathrm{u}}=2 \mathrm{~V}_{\mathrm{u}} \\
\text { with }^{[2]} \quad \mathrm{V}_{\mathrm{u}}=\Phi 0.1275 \sqrt{f_{c}^{\prime}} b h_{f}+V_{f r p}
\end{gathered}
$$

where $\Phi$ is strength reduction factor $(0.75), h_{f}$ is effective height $(\mathrm{mm}), \mathrm{f}_{\mathrm{c}}^{s}$ is AAC's design value of compressive strength (MPa). Accordingly, the peak load of RAP predicted by Eq. (4), and (5) is $12.1 \mathrm{kN}, 5.6 \%$ higher than experimental result $11.42 \mathrm{kN}$.

The function of CFRP strengthened plates is similar to bending resistance reinforcement, having no contribution to shear strength directly ${ }^{[3]}$, but increasing the flexural rigidity of AAC panel, preventing the panel from bending failure, releasing the shear capacity of concrete. Therefore it changes the failure model of FRP/AAC panel from bending failure to shear failure. The damage mode of RAP and UCPAP was similar (shear failure), different from that of PAP (bending failure at mid-span), and the peak loads of RAP and UCPAP were close, $11.42 \mathrm{kN}$ (RAP) and $11.59 \mathrm{kN}$ (UCPAP), respectively.

As for BCRAP, the bidirectional CFRP plates enhance the shear capacity of AAC. Moment provided by the wrapping CFRP sheet should be included. Chen and Teng ${ }^{[4]}$ suggested the shear strength provided by FRP for debonding as:

$$
V_{\text {frp }}=2 D_{\text {frp }} 0.427 \beta_{\mathrm{w}} \beta_{L} \sqrt{\frac{E_{\text {frp }} \sqrt{f_{\mathrm{f}}^{p}}}{t_{\text {frp }}}} t_{\text {frp }} w_{\text {frp }} h_{\text {frp }, e} / s_{\text {frp }}
$$

where $\sigma_{\text {frp,max }}$ is the maximum stress in CFRP sheet along shear crack, $t_{\text {frp }}$ is thickness of CFRP sheet, $\mathrm{w}_{\text {frp }}$ is width of CFRP sheet, $\mathrm{h}_{\text {frp, }}$ is effective height of CFRP sheet stick to panel's sides. Sfrp is clear distance between CFRP stripes, which was $300 \mathrm{~mm}$ in this study. $\mathrm{D}_{\text {frp }}$ is stress distribution coefficient, is defined as follows:

$$
\mathrm{D}_{\text {frp }}=\left\{\begin{array}{cc}
\frac{2}{\pi \lambda} \frac{1-\cos (\pi h / 2)}{\sin (\pi h / 2)} & \lambda \leq 1 \\
1-\frac{\pi-2}{\pi \imath} & \lambda>1
\end{array}\right.
$$


The shear strength provided by CFRP predicted by Eq. (6), is $5.25 \mathrm{kN}$, then the peak load $\mathrm{P}_{\mathrm{u}}$ of BCRAP predicted by Eq. (5), is $22.6 \mathrm{kN}, 8.4 \%$ higher than experimental result $20.7 \mathrm{kN}$.

As shown in Fig. 5(b), the analysis of FRP/AAC panels can be deduced based on internal force equilibrium. The algebraic sum of compressive forces is equal to that of tensile forces in FRP/AAC panel at any cross section,

$$
\mathrm{T}_{\text {frp }}+\mathrm{T}_{\mathrm{s}}+\mathrm{T}_{\mathrm{AAC}}=\mathrm{C}_{\mathrm{frp}}+\mathrm{C}_{\mathrm{s}}+\mathrm{C}_{\mathrm{AAC}}
$$

The tensile strength contribution of AAC to the composite pane is not significant, therefore it was ignored. Similarly, the contribution of CFRP in compressive forces is considered none, i.e. Therefore the equilibrium equation becomes

$$
\mathrm{T}_{\mathrm{frp}}+\mathrm{T}_{\mathrm{s}}=\mathrm{C}_{\mathrm{s}}+\mathrm{C}_{\mathrm{AAC}}
$$

Where $\mathrm{T}_{\text {frp }}=\mathrm{E}_{\mathrm{frp}} \varepsilon_{\text {frp }} b \mathrm{t}_{\mathrm{frp}, \mathrm{g}}, \mathrm{T}_{\mathrm{s}}=9 \mathrm{E}_{\mathrm{s}} \boldsymbol{\varepsilon}_{\mathrm{st}} \pi \mathrm{r}^{2}, \mathrm{Cs}=9 \mathrm{E}_{\mathrm{s}} \boldsymbol{\varepsilon}_{\mathrm{sc}} \pi \mathrm{r}^{2}, \quad \mathrm{C}_{\mathrm{AAC}}=0.5 \mathrm{E}_{\mathrm{c}} \varepsilon_{\mathrm{c}}$, and y is depth of neutral axis $(\mathrm{mm})$.

The total moment contributed from the four forces above is

$$
\mathrm{M}=0.5(\mathrm{~h} / 2-\mathrm{y} / 3) \mathrm{E}_{\mathrm{c}} \varepsilon_{\mathrm{c}} \mathrm{by}+9\left(\mathrm{~d}_{\mathrm{s}}-\mathrm{h} / 2\right) \varepsilon_{\mathrm{st}} \cdot \mathrm{E}_{\mathrm{st}} \pi \mathrm{r}^{2}+9\left(\mathrm{~d}_{\mathrm{s}}-\mathrm{h} / 2\right) \varepsilon_{\mathrm{sc}} \cdot \mathrm{E}_{\mathrm{st}} \pi \mathrm{r}^{2}+\mathrm{h} / 2 \cdot \mathrm{E}_{\mathrm{frp}} \varepsilon_{\mathrm{frp}} \mathrm{bt}_{\mathrm{fr} p, \mathrm{~g}}
$$

The geometric deformation relationship of the simply supported partially FRP/AAC panel is shown in Fig. 5(a ${ }^{[11]}$. Accordingly, the relationship between cross-sectional curvature $\theta$ and deflection $\omega$ can be derived by the following equations: $\theta=2 \omega / \mathrm{L}$

where $\mathrm{L}$ is effective length of the panel.

$$
\text { Deflection } \omega \text { can be obtained as: } \omega=\int_{0}^{500} \frac{\mathrm{Ls}}{2 \mathrm{y}^{\prime}} \mathrm{dx}
$$

where $y^{s}$ is distance of strain position to neutral axis.

As summarized in Tab. 4, the depth of neutral axis $y$, and the maximum deflection at mid span $\omega_{\max }$ can be calculated according to Eq. (9), (10) and (12). In addition, the equilibrium equation of forces is also listed in Tab.4.

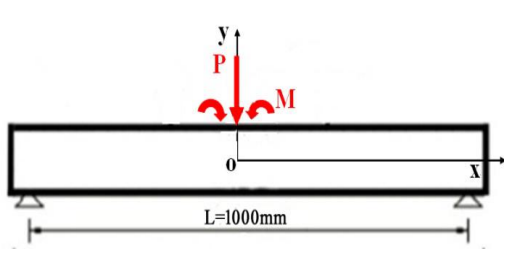

(a)

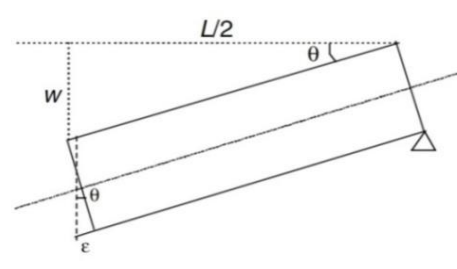

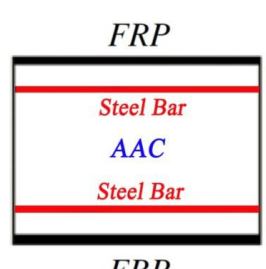

FRP

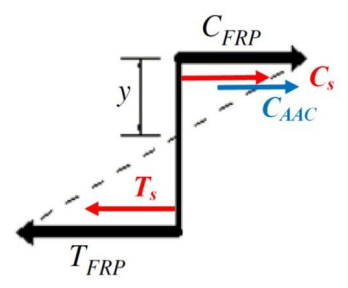

(b)

Fig.5 (a)Deformation diagram of simply supported beams, and (b)force schematic diagram for FRP/AAC panel's crossing section

Table 4 Summary of neutral axis depth and the maximum deflection at mid-span

\begin{tabular}{|c|c|c|c|c|c|c|c|c|c|}
\hline \multirow{2}{*}{ Panel } & \multirow{2}{*}{$\begin{array}{c}\text { Neutral } \\
\text { axis depth }\end{array}$} & \multicolumn{3}{|c|}{ Material strain } & \multicolumn{3}{c|}{ Material stress } & Maximum deflection & $\begin{array}{c}\text { Equilibrium equation } \\
\text { of forces }\end{array}$ \\
\cline { 4 - 10 } & AAC & FRP & Steel bar & AAC & FRP & Steel bar & at mid-span & \\
\hline RAP & $39 \mathrm{~mm}$ & 0.0011 & - & 0.0013 & $1.98 \mathrm{MPa}$ & - & $273 \mathrm{MPa}$ & $3.68 \mathrm{~mm}$ & $\mathrm{~T}_{\mathrm{s}}=\mathrm{C}_{\mathrm{s}}+\mathrm{C}_{\mathrm{AAC}}$ \\
\hline UCPAP & $57 \mathrm{~mm}$ & 0.0014 & 0.0011 & - & $2.52 \mathrm{MPa}$ & $154 \mathrm{MPa}$ & - & $3.14 \mathrm{~mm}$ & $\mathrm{~T}_{\text {frp }}=\mathrm{C}_{\mathrm{AAC}}$ \\
\hline BCRAP & $51 \mathrm{~mm}$ & 0.0016 & 0.0015 & 0.0010 & $2.88 \mathrm{MPa}$ & $210 \mathrm{MPa}$ & $273 \mathrm{MPa}$ & $3.39 \mathrm{~mm}$ & $\mathrm{~T}_{\mathrm{fip}}+\mathrm{T}_{\mathrm{s}}=\mathrm{C}_{\mathrm{s}}+\mathrm{C}_{\mathrm{AAC}}$ \\
\hline
\end{tabular}




\section{Validation}

As seen in Tab. 5, the total shear strength of specimens and the maximum deflection at mid span are listed. The difference between the nominal and experimental values is listed, ranging from $4.2 \%$ to $8.4 \%$ for maximum load, and ranging from $1.9 \%$ to $8.5 \%$ for critical mid-span deflection. This close convergence illustrates that the proposed model can be used to predict the shear strength and deflection of FRP/AAC panel.

Table 5 Comparison of predicted results and experimental data

\begin{tabular}{ccccccc}
\hline \multirow{2}{*}{ Panel } & \multicolumn{3}{c}{ Maximum Load } & \multicolumn{3}{c}{ Critical mid-span deflection } \\
& Predicted & Experimental & Difference & Predicted & Experimental & Difference \\
\hline PAP & $1.2 \mathrm{kN}$ & $<2 \mathrm{kN}$ & - & & & \\
RAP & $12.1 \mathrm{kN}$ & $11.42 \mathrm{kN}$ & $5.6 \%$ & 3.68 & $4.02 \mathrm{~mm}$ & $8.5 \%$ \\
UCPAP & $12.1 \mathrm{kN}$ & $11.59 \mathrm{kN}$ & $4.2 \%$ & 3.14 & $3.08 \mathrm{~mm}$ & $1.9 \%$ \\
BCRAP & $22.6 \mathrm{kN}$ & $20.70 \mathrm{kN}$ & $8.4 \%$ & 3.39 & $3.54 \mathrm{~mm}$ & $4.2 \%$ \\
\hline
\end{tabular}

\section{Conclusions}

The following conclusions can be drawn from this study:

1. Shear failure is the damage mode of FRP/AAC panels, because AAC is brittle materials with low strength.

2. The sandwich panels are composed of three materials: FRP, steel bar, and AAC. The skin (FRP) and steel bar carry the bending stresses, while the core (AAC) carries the shear stresses. Although CFRP do not increase the shear strength directly, it enhances the flexural rigidity of AAC panel, releasing the shear capacity of concrete.

3. Because of low shear strength of AAC, the key influence factor of FRP strengthening is bonding effect between FRP and AAC.

4. The high tensile strength of CFRP is not able to be fully used, because of the low ultimate stress of AAC. Elastic modulus of FRP rather than tensile strength has greater influence on strengthening effect of FRP/AAC composite structure.

\section{References}

[1] Bo Wang, Peng Wang, Yishun Chen, etc. Blast responses of CFRP strengthened autoclaved aerated cellular concrete panels. Construction and Building Materials, 2017 (157): 226-236.

[2] ACI 318-05, Building Code Requirement for Structural Concrete and Commentary, American Concrete Institute (ACI), Detroit, USA; 2005.

[3] Jinguang Teng, Jianfei Chen, S.T.Smith, Li Lin. Strengthened RC Structures, China Architecture \& Building Press, Beijing, China; 2005.

[4] J.F. Chen, J.G. Teng. Shear capacity of FRP strengthened RC beams: FRP debonding, Construction \& Building Materials. 2003; 17 (1): 27-41.

[5] Li Chen, Qin Fang, Jing-Chun Liu, Heng-bo Xiang. Nonlinear Analysis of Blast Performance of Partially Prestressed RC Beams, International Journal of Protective Structures. 2001; 2(3): 295-314. 